Clinical oncohematology. 2019;12(4):406-15

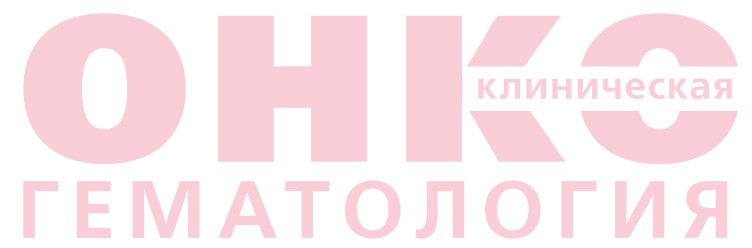

ТРАНСПЛАНТАЦИЯ КОСТНОГО МОЗГА

\section{Infectious Complications after Haploidentical Hematopoietic Stem Cells Transplantation in Patients with High-Risk Tumors of Hematopoietic and Lymphoid Tissues: A Single-Center Experience}

\section{YuS Osipov', SS Bessmeltsev2, GN Salogub ${ }^{1}$, VV Ivanov', ES Mikhailov', NA Zhukova', AV Chechetkin ${ }^{2}$}

\section{Ю.С. Осипов', С.С. Бессмельцев², Г.Н. Салогуб', В.В. Иванов', Е.С. Михайлов', Н.А. Жукова', А.В. Чечеткин ${ }^{2}$}

1 ФГБУ «НМИЦ им. В.А. Алмазова» Минздрава России, ул. Аккуратова, д. 2, Санкт-Петербург, Российская Федерация, 197341

2 ФГБУ «Российский НИИ гематологии и трансфузиологии ФМБА», ул. 2-я Советская, д. 16, Санкт-Петербург, Российская Федерация, 191024

\section{РЕФЕРАТ}

Цель. Определить частоту развития вирусных, бактериальных и грибковых инфекций в посттрансплантационный период, оценить прогностическое значение инфекций и их влияние на ранние и отдаленные результаты гаплоидентичной трансплантации гемопоэтических стволовых клеток (гаплоТГСК).

Материалы и методы. В ретроспективное исследование был включен 61 пациент старше 18 лет с онкогематологическими заболеваниями высокого риска. С 2015 по 2018 г. всем пациентам выполнена гаплоТГСК. Медиана наблюдения после гаплоТГСК составила 12,5 мес. (376 дней, диапазон 6-1202 дня). Больные разделены на две группы. Первая $(n=26)$ - гаплоТГСК выполнена в качестве терапии «спасения» («salvage»). В нее включены больные с рефрактерным течением опухоли и отсутствием ремиссии ко времени гаплоТГСК либо с ранними рецидивами после HLA-совместимых родственных или неродственных аллоТГСК. Вторая группа $(n=35)$ - гаплоТГСК выполнена при достижении оптимального предтрансплантационного статуса («non-salvage»).

Результаты. Частота реактивации цитомегаловирусной (CMV) инсекции, развития инвазивного микоза и бактериальных инфекций составила 70,4, 11,5 и 75,4 \% соответственно. Влияния реактивации CMV-инфекции или развития инвазивного микоза на 35- и 100-дневную общую выживаемость (ОВ) не отмечено. Бактериальные инфекции впервые были стратифицированы по степени тяжести в соответствии с консенсусом Sepsis 3, что позволило выделить группы пациентов с неблагоприятным прогнозом. Тяжелые фрормы бактериальных инфекций (сепсис, септический шок) коррелировали с ухудшением как краткосрочных, так и отдаленных результатов, особенно у пациентов вне ремиссии к мо-
${ }^{1}$ VA Almazov National Medical Research Center, 2 Akkuratova str., Saint Petersburg, Russian Federation, 197341

${ }^{2}$ Russian Research Institute of Hematology and Transfusiology, 16 2-ya Sovetskaya str., Saint Petersburg, Russian Federation, 191024

\section{ABSTRACT}

Aim. To determine the incidence of viral, bacterial, and fungal infections in post-transplant period and to assess the prognostic value of infections and their influence on early and long-term results of haploidentical hematopoietic stem cells transplantation (haplo-HSCT).

Materials \& Methods. Retrospective study included 61 patients older than 18 years with high-risk oncohematological diseases. In the period from 2015 to 2018 all patients received haplo-HSCT. Median follow-up after haplo-HSCT was 12.5 months (376 days, range 6-1202). Patients were divided into two groups. The first group $(n=26)$ received haplo-HSCT as salvage therapy. It included patients with refractory tumors without remission by the start of haplo-HSCT and patients with early relapses after HLA-matched related or unrelated allo-HSCT. The second group $(n=35)$ received haplo-HSCT on reaching the optimal pretransplant status ("non-salvage").

Results. The incidence of cytomegalovirus (CMV) reactivation, invasive mycosis, and bacterial infections was $70.4 \%$, $11.5 \%$, and $75.4 \%$, respectively. CMV reactivation and invasive mycosis did not affect either the 35 - or the 100-day overall survival (OS). For the first time bacterial infections were stratified based on severity according to Sepsis 3 consensus, which allowed to identify groups of patients with unfavorable prognosis. Severe bacterial infections (sepsis and septic shock) correlated with worse early and long-term results, especially in patients without remission by the start of haplo-HSCT, whereas febrile neutropenia/bloodstream infection did not affect OS. On the whole, mortality associated with bacterial infections was $26.2 \%$.

Conclusion. The main factor affecting early lethality after haplo-HSCT is a severe bacterial infection. The key risk factor is lack of remission by the start of haplo-HSCT. Sepsis 
менту выполнения гаплоТГСК, в то время как развитие фебрильной нейтропении/инфекций кровотока не влияло на ОВ. В целом смертность, связанная с бактериальными инфекциями, составила 26,2 \%.

Заключение. Основным фактором, влияющим на раннюю летальность после гаплоТГСК, является развитие тяжелых бактериальных инфекций. Ведущий фактор риска отсутствие ремиссии ко времени выполнения гаплоТГСК. Критерии Sepsis 3 могут использоваться в период постцитостатической цитопении, что позволит выделить группу больных с максимально неблагоприятным прогнозом (развитие септического шока). Внедрение в рутинную клиническую практику современных методов инфекционного контроля (генотипирование штаммов со множественной лекарственной устойчивостью и своевременное определение стратегии антимикробной химиотерапии с учетом полученных результатов) может способствовать улучшению результатов лечения этой категории больных.

Ключевые слова: гаплоидентичная трансплантация гемопоэтических стволовых клеток, инфекционные осложнения, сепсис, септический шок, реактивация цитомегаловирусной инфекции, инвазивный микоз.

Получено: 11 апреля 2019 г.

Принято в печать: 18 сентября 2019 г.

Для переписки: Юрий Сергеевич Осипов, ул. Аккуратова, д. 2, СанктПетербург, Российская Федерация, 197341; тел.: +7(812)702-37-65; e-mail: osipov_yus@almazovcentre.ru

Для цитирования: Осипов Ю.С., Бессмельцев С.С., Салогуб Г.Н. и др. Инфекционные осложнения после гаплоидентичной трансплантации гемопоэтических стволовых клеток у пациентов с опухолями кроветворной и лимфоидной тканей высокого риска: опыт одного центра. Клиническая онкогематология. 2019;12(4):406-15.

DOI: 10.21320/2500-2139-2019-12-4-406-415
3 criteria can be applied in the period of postcytostatic cytopenia to identify the group of patients with most unfavorable prognosis (septic shock). The implementation of current infection control methods (genotyping of multiple drug resistant strains and timely determining the strategy of antimicrobial chemotherapy on the basis of the results obtained) into everyday clinical practice can improve the treatment outcomes in this category of patients.

Keywords: haploidentical hematopoietic stem cells transplantation, infectious complications, sepsis, septic shock, cytomegalovirus reactivation, invasive mycosis.

Received: April 11, 2019

Accepted: September 18, 2019

For correspondence: Yurii Sergeevich Osipov, 2 Akkuratova str., Saint Petersburg, Russian Federation, 197341; Tel.: +7(812)702-37-65; e-mail: osipov_yus@almazovcentre.ru

For citation: Osipov YuS, Bessmeltsev SS, Salogub GN, et al. Infectious Complications after Haploidentical Hematopoietic Stem Cells Transplantation in Patients with High-Risk Tumors of Hematopoietic and Lymphoid Tissues: A Single-Center Experience. Clinical oncohematology. 2019;12(4):406-15 (In Russ).

DOI: 10.21320/2500-2139-2019-12-4-406-415

\section{ВВЕДЕНИЕ}

Несмотря на внедрение в клиническую практику новых лекарственных средств для лечения онкогематологических заболеваний, зачастую единственным методом воздействия на опухоль при рецидивах/ рефрактерных формах болезни является аллогенная трансплантация костного мозга/гемопоэтических стволовых клеток (ГСК).

Исторически «идеальным» считался полностью совместимый родственный донор, при отсутствии которого обсуждалось выполнение аллоТГСК от неродственного HLA-идентичного донора. Последний вариант не всегда применим, особенно если речь идет о пациентах с высоким риском рецидивов/прогрессирования, когда сроки проведения аллоТГСК имеют решающее значение. К тому же далеко не для каждого пациента может быть найден подходящий донор. В реальной клинической практике такая возможность имеется только у 40-45 \% пациентов $[1,2]$.

В качестве приемлемой опции в такой ситуации может рассматриваться гаплоидентичная ТГСК
(гаплотГСК). Ранее проведение гаплоТГСК сопровождалось высоким уровнем летальности, связанной с трансплантацией, и высокой частотой развития тяжелой реакции «трансплантат против хозяина» (РТПХ). Это ограничивало применение гаплоТГСК. В течение последнего десятилетия после появления работ L. Luznik и соавт. [2, 3] о способе профилактики РТПХ за счет снижения Т-клеток in vivo высокими дозами циклофосфамида гаплоТГСК стала широко применяться в клинической практике. По данным ряда авторов $[2,4,5]$, частота развития острой и хронической РТПХ среди реципиентов гаплоидентичных и полностью совместимых ГСК при использовании указанной выше методики оказалась сопоставимой. Кроме того, в ряде исследований было показано преимущество в общей выживаемости (ОВ) и выживаемости без прогрессирования при выполнении гаплоТГСК перед трансплантацией от полностью совместимого донора при рефрактерном течении онкогематологических заболеваний $[4,6]$.

В то же время нерешенной проблемой остаются инфекционные осложнения раннего посттрансплантационного периода [7-11]. Их частота при выпол- 
нении гаплоТГСК составляет, по данным разных авторов, от 30 до 90 \% [12-16]. К настоящему времени публикации, в которых представлены частота развития и прогностическое значение инфекций у этой категории больных, ограничены единственным крупным исследованием Francophone Society of Stem Cell Transplantation and Cellular Therapy (SFGM-TC) [9]. При участии 30 центров ретроспективному анализу подвергнута частота развития инфекционных осложнений у 381 реципиента гаплоидентичных ГСК. Частота бактериальных инфекций составила $57,4 \%$, вирусных - 34,1 \%, инвазивного микоза $6 \%$.

Цель настоящей работы - определить частоту развития вирусных, бактериальных и грибковых инфекций в посттрансплантационный период, а также оценить прогностическое значение инфекций и их влияние на ранние и отдаленные результаты гаплоТгСК. Кроме того, в работе впервые оценена частота развития тяжелых форм бактериальных инфекций (сепсиса, септического шока).

\section{МАТЕРИАЛЫ И МЕТОДЫ}

В исследование включен 61 пациент старше 18 лет с онкогематологическими заболеваниями высокого риска. Всем больным в период с 2015 по 2018 г. выполнена гаплоТГСК. В зависимости от статуса заболевания ко времени проведения гаплоТГСК все пациенты были разделены на две группы. В первой группе $(n=26)$ гаплоТГСК проводилась в качестве терапии «спасения» («salvage»). В нее включены пациенты с рефрактерным течением основного заболевания и отсутствием ремиссии на момент ТГСК либо больные с ранними рецидивами после HLA-совместимых родственных или неродственных ТГСК. Во второй группе $(n=35)$ гаплоТГСК выполнялась при достижении оптимального предтрансплантационного статуса («nonsalvage»). Характеристика пациентов представлена в табл. 1.

Все пациенты получили режим кондиционирования со сниженной интенсивностью: флударабин 180 мг/м² + бусульфан 8 мг/кг внутрь. Профилактика РТПХ включала высокие дозы циклофосфамида (50 мг/кг/сут) в Д+3 и Д+4 после гаплоТГСК, с Д+5 начиналась базисная иммуносупрессивная терапия ингибиторами кальциневрина (такролимус или циклоспорин А) в сочетании с микофенолата мофетилом 45 мг/кг (максимальная доза 3000 мг/ сут). Прием микофенолата мофетила продолжался до 35 дней после гаплоТГСК, базисная иммуносупрессивная терапия ингибиторами кальциневрина до 100-180 дней в зависимости от переносимости, токсичности и риска рецидива основного заболевания. У всех больных, согласно рекомендациям по предотвращению инфекционных осложнений после ТГСК [17], параллельно с режимом кондиционирования проводилась профилактика: противовирусная ацикловиром 600 мг/сут, антибактериальная с использованием фторхинолонов (ципрофлоксацин или левофлоксацин), пневмоцистной инфекции триметопримом/сульфаметоксазолом. Первичная
Таблица 1. Характеристика пациентов, включенных в исследование

\begin{tabular}{lc}
\hline \multicolumn{1}{c}{ Показатель } & Значение \\
\hline Медиана (диапазон) возраста, лет & 40,9 (18-66) \\
Пол & $29(47,5 \%)$ \\
Мужчины & 32 (52,5 \%) \\
Женщины & \\
Диагноз & 33 (54,1\%) \\
Острые миелоидные лейкозы & $15(24,6 \%)$ \\
Острый лимфобластный лейкоз & $3(4,9 \%)$ \\
Лимфома Ходжкина & $3(4,9 \%)$ \\
Неходжкинские лимфомы и Мм & $7(11,5 \%)$ \\
Хронические Рһ-негативные миелопролифера- & \\
тивные заболевания и ХМЛ &
\end{tabular}

Статус заболевания ко времени гаплоТГСК

«Salvage»

«Non-salvage»

$26(42,6 \%)$

$35(57,4 \%)$

Тип режима кондиционирования

КСИ

$61(100 \%)$

MAK

0

Источник трансплантата

гCK

$59(96,7 \%)$

Костный м0зг

$2(3,3 \%)$

Медиана (диапазон) клеток CD34+ в трансплантате, $\times 10^{6} / \mathrm{kг}$

$5,9(3,8-6,4)$

Медиана (диапазон) времени до восстановления нейтрофилов, дни

Первичное неприживление трансплантата

$22,5(6,0-29,4)$

$2(3,8 \%)$

гаплоТГСК - гаплоидентичная трансплантация гемопоэтических

стволовых клеток; КСИ - кондиционирование со сниженной

интенсивностью; МАК - миелоаблативное кондиционирование; ММ -

множественная миелома; ХМЛ - хронический миелолейкоз.

противогрибковая профилактика флуконазолом начиналась с 1-го дня агранулоцитоза и продолжалась до момента восстановления нейтрофилов до более 1000 /мкл. Вторичную профилактику вориконазолом или эхинокандинами получало 14 (22,9%) пациентов с инвазивной грибковой инфекцией в анамнезе.

В работе оценивались частота и сроки развития бактериальных, вирусных (реактивация цитомегаловируса - CMV) и грибковых инфекций у реципиентов гаплоидентичных ГСК, а также их влияние на ОВ. Для диагностики инвазивного микоза применялись критерии EORTS/MSG [18], для характеристики бактериальных инфекций использовались критерии Sepsis 3 [19]. Пациенты с доказанной или подозреваемой бактериальной инфекцией, наличием органной дисфункции и имевшие более 2 баллов при оценке состояния по шкале SOFA (степень тромбоцитопении не учитывалась, поскольку цитопенический синдром носит постцитостатический характер) были определены как больные с сепсисом. При наличии рефрактерной к волемической нагрузке артериальной гипотензии с потребностью в назначении вазопрессорных препаратов в сочетании с повышением лактата сыворотки более 2 ммоль/л устанавливался диагноз септического шока (критерии Sepsis 3) [19]. Пациенты с сепсисом и септическим шоком были определены как больные с тяжелыми формами бактериальных инфекций.

Учитывая максимальную частоту развития бактериальных инфекций в период агранулоцитоза 
до нейтрофильного приживления трансплантата (восстановление уровня нейтрофилов более 500/мкл в течение 3 последовательных дней), этот показатель оценивался в первые 35 дней после гаплоТГСК. Частота реактивации CMV-инфекции и развития инвазивного микоза de поvо оценивалась в течение первых 100 дней после гаплоТГСК.

\section{Статистический анализ}

Анализ полученных данных проводился с использованием программного обеспечения IBM SPSS Statistics 22. Для характеристики результатов были определены средние значения, медианы, доли в процентах. Для построения кривых ОВ по КаплануМейеру продолжительность жизни рассчитывалась от дня выполнения гаплоТГСК до дня смерти или даты последнего контакта с пациентом. Конкурирующих состояний (смерть от прогрессирования или по альтернативным причинам) не выявлено, поэтому данные показатели не учитывались. Статистически значимым считалось различие при $p<0,05$.

\section{РЕЗУЛЬТАТЫ}

Медиана наблюдения за пациентами составила 12,5 мес. (376 дней, диапазон 6-1202 дня, стандартная ошибка 48,84 дня). В течение первых 30 дней после гаплоТГСК 8 (12,9\%) пациентов умерли от бактериальных инфекционных осложнений до восстановления уровня нейтрофилов. Среди остальных 53 больных первичное неприживление трансплантата, определяемое как отсутствие восстановления донорского гемопоэза в течение 30 дней от момента ТГСК, зарегистрировано у 2 (3,8 \%). Показатель 1-летней ОВ в целом составил 49,3 \%. При этом выявлено статистически значимое преимущество в ОВ у больных из группы «non-salvage» $(68,7$ vs $25 \%$; $p<0,001)$ (рис. 1 и 2).

\section{Инфекционные осложнения после гаплотГСК}

В течение первых 35 и 100 дней после гаплотГСК было зарегистрировано 87 и 96 эпизодов инфекционных осложнений: реактивация CMV-инфекции 35 (57,3\%) и 43 (70,4 \%), бактериальные инфекции 46 (75,4 \%) и 46 (48 \%), развитие инвазивного микоза - $6(9,8 \%)$ и $7(11,5 \%)$ соответственно. Таким образом, 90,6 \% всех осложнений были зарегистрированы в течение 1 мес. после гаплоТГСК. Медиана времени до развития бактериальных инфекций составила 10,9 дня, до реактивации CMV-инфекции 25,3 дня. Частота развития инвазивного микоза в течение 100 дней после гаплоТГСК составила 11,5 \% (рис. 3-5).

\section{Реактивация цитомегаловирусной инфекции}

В течение первых 100 дней после гаплотГСК было зарегистрировано 43 (69 \%) случая реактивации CMV-инфекции на основании выявления методом ПЦР более 1000 копий ДНК CMV/мл крови. При медиане наблюдения за пациентами 376 дней не было зарегистрировано ни одного случая развития CMV-болезни. Согласно существующим рекоменда- циям, все пациенты получали терапию аналогами нуклеозидов (ганцикловир, валганцикловир). Ни в одном случае не зарегистрировано резистентности к данной группе препаратов. При анализе выживаемости не выявлено негативного прогностического влияния реактивации CMV-инфекции на 100-дневную OB $(p=0,824)$ (рис. 6).

\section{Развитие инвазивного микоза}

При анализе частоты инвазивных грибковых инфекций рассматривались только случаи развития инвазивного микоза (ИМ) de nоvo. В течение первых

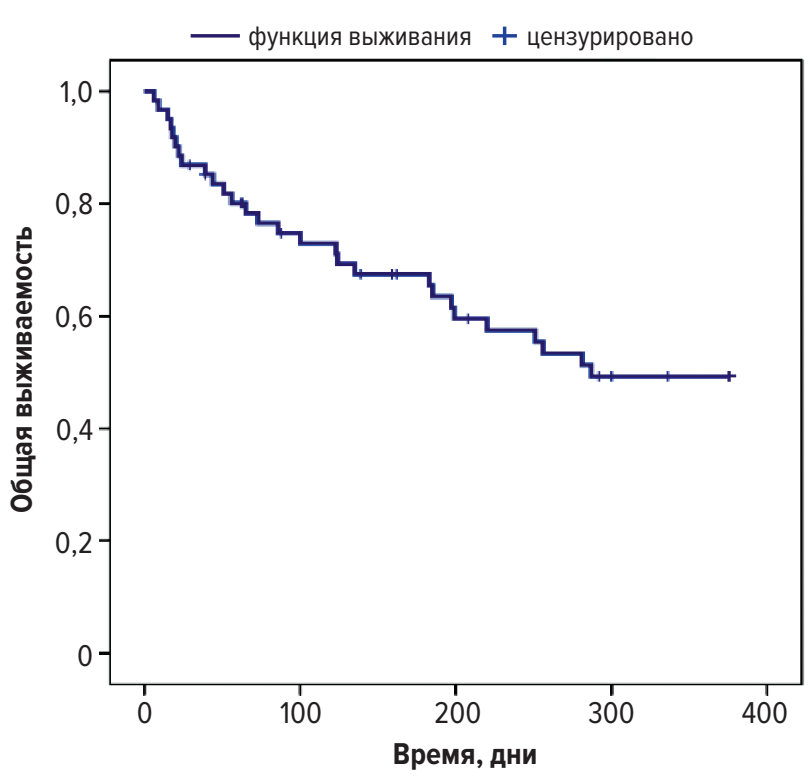

Рис. 1. Общая выживаемость всех пациентов $(n=61)$ на 376 дней наблюдения

Fig. 1. Overall survival of all patients $(n=61)$ during the 376 -day follow-up

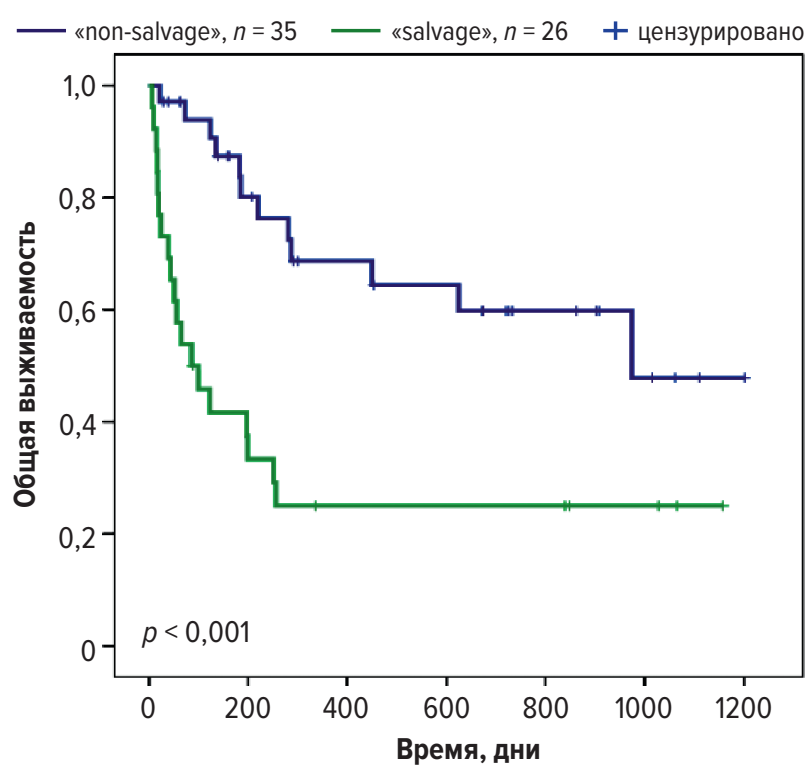

Рис. 2. Общая выживаемость в группах пациентов с различным статусом заболевания («salvage» и «non-salvage») ко времени гаплотГСК

Fig. 2. Overall survival in the groups of patients with different disease statuses ("salvage" and "non-salvage") by the start of haploHSCT 


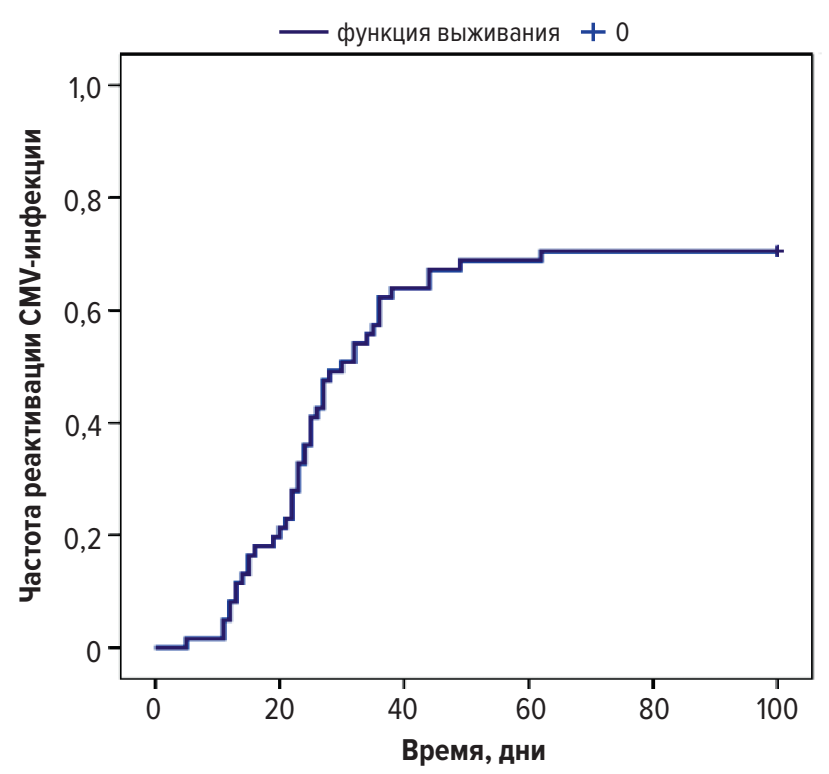

Рис. 3. 100-дневная частота реактивации цитомегаловирусной (CMV) инфекции после гаплоТГСК

Fig. 3. The 100-day incidence of cytomegalovirus (CMV) reactivation after haplo-HSCT

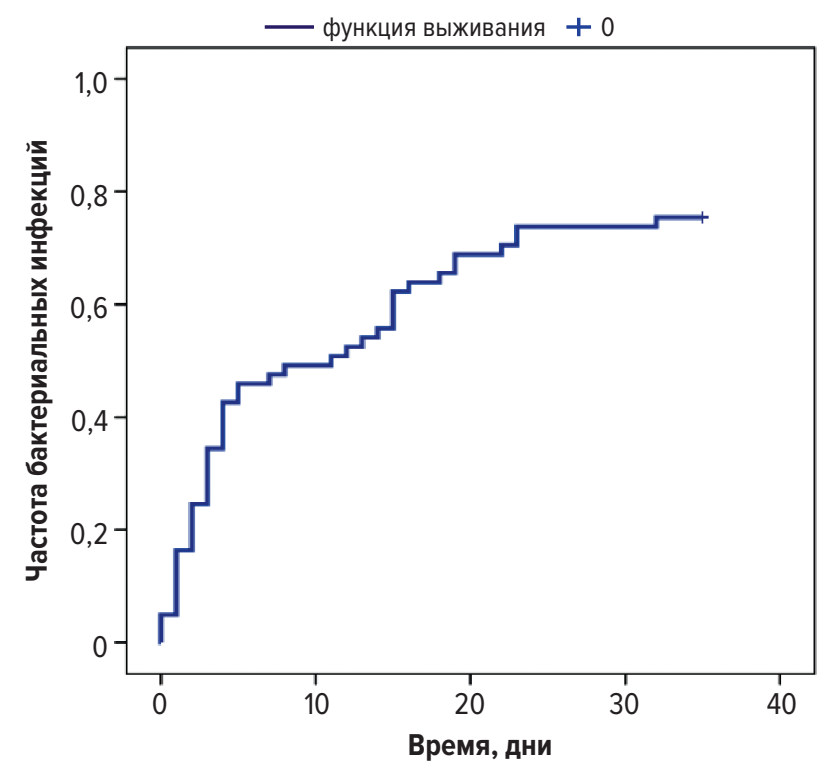

Рис. 5. 35-дневная частота развития бактериальных инфекций после гаплоТГСК

Fig. 5. The 35-day incidence of bacterial infections after haplo-HSCT

100 дней после гаплоТГСК было зарегистрировано 7 эпизодов ИМ (6 - вероятный инвазивный аспергиллез легких, 1 - хронический диссеминированный гепатолиенальный кандидоз). В последующем у всех больных с ИМ был достигнут полный ответ в результате противогрибковой терапии. У пациентов, получавших ко времени гаплоТГСК вторичную противогрибковую профилактику, случаев развития прорывных инфекций (связанных с формированием рефрактерного штамма либо развитием ИМ с отсутствием чувствительности к препарату) не отмечено. Наличие ИМ в посттрансплантационный период не отразилось на 100-дневной ОВ пациентов (рис. 7).

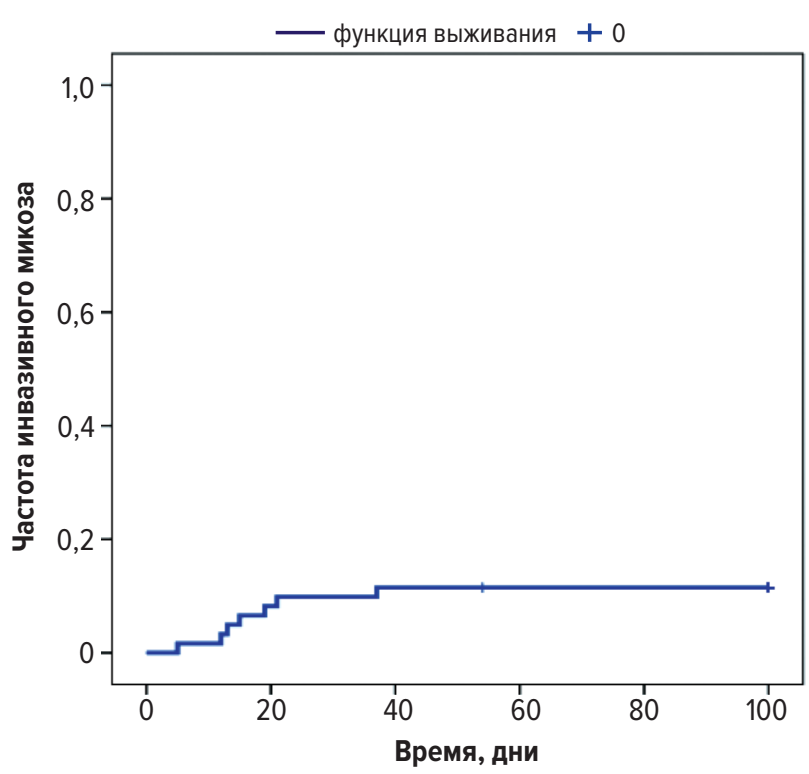

Рис. 4. 100-дневная частота развития инвазивного микоза после гаплоТГСК

Fig. 4. The 100-day incidence of invasive mycosis after haplo-HSCT

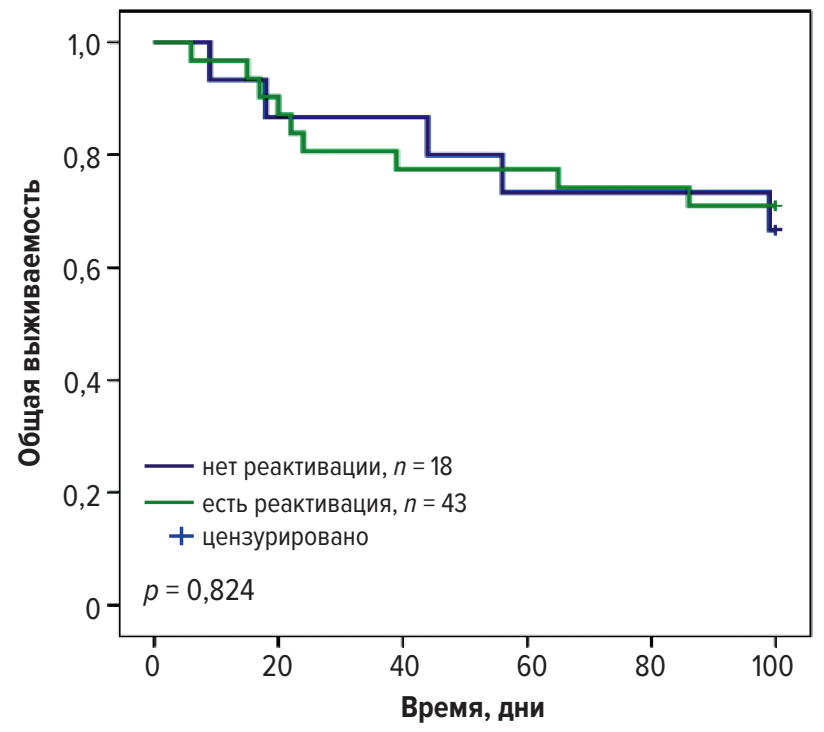

Рис. 6. Общая выживаемость пациентов с и без реактивации CMV-инфекции после гаплоТГСК

Fig. 6. Overall survival of patients with and without CMV reactivation after haplo-HSCT

\section{Бактериальные инфекции}

В целом сам факт развития бактериальной инфекции не оказывал негативного прогностического влияния на показатели 30- и 100-дневной ОВ (рис. 8 и 9).

Для характеристики степени тяжести инфекционного процесса у всех больных были применены критерии Sepsis 3 (ретроспективно, у пациентов, которым ТГСК выполнялась в 2015-2016 гг.). Согласно данному консенсусу, были выделены такие формы бактериальной инфекции, как фебрильная нейтропения, инфекция кровотока, сепсис, септический шок. В целом частота развития бактериальных осложнений у пациентов из групп «salvage» и «non-salvage» не от- 


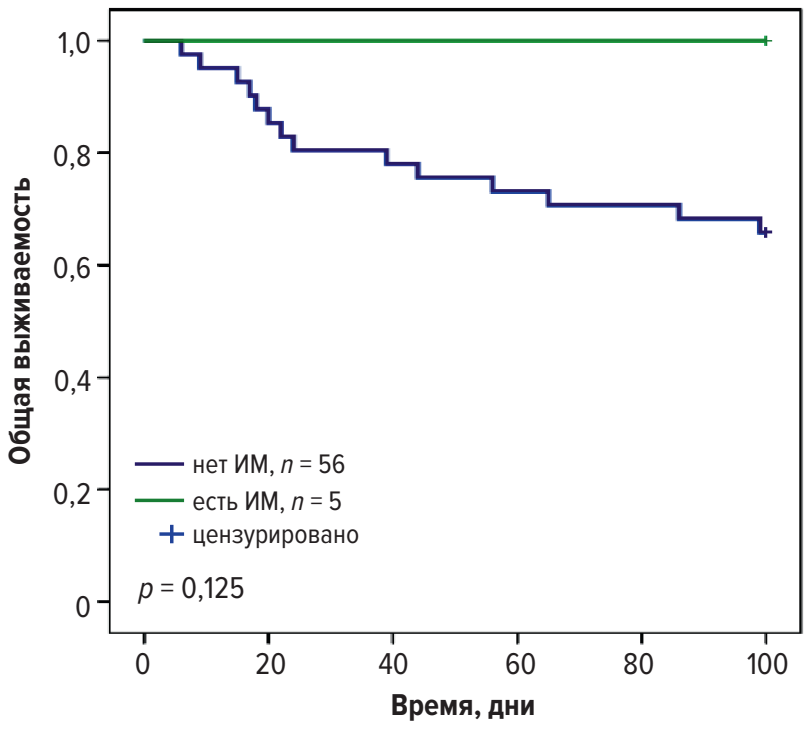

Рис. 7. Общая выживаемость пациентов с и без инвазивного микоза (ИМ) после гаплоТГСК

Fig. 7. Overall survival of patients with and without invasive mycosis (ИM) after haplo-HSCT

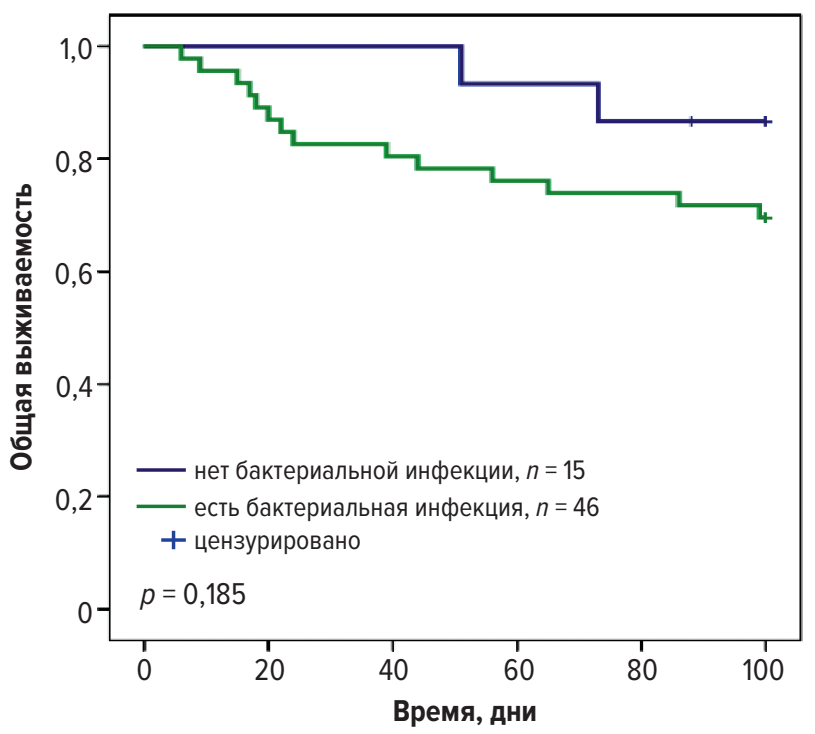

Рис. 9. Прогностическое влияние развития бактериальной инфекции на 100-дневную общую выживаемость

Fig. 9. Prognostic influence of bacterial infections on the 100-day overall survival

личалась - 76,9 и 74,3 \% соответственно (в общей популяции больных - 74 \%). Тем не менее в группе пациентов с исходно неблагоприятным прогнозом зарегистрирована большая частота тяжелых форм бактериальных инфекций (сепсис и септический шок) $-57,7$ vs 31,4 \% ( $p<0,05)$. В то же время в группе пациентов с достижением оптимального статуса ко времени гаплоТГСК в структуре бактериальных осложнений преобладали такие формы, как фебрильная нейтропения и инфекция кровотока, - 42,9 vs 19,2 \% (табл. 2).

Отдельно были проанализированы результаты лечения пациентов с сепсисом и септическим шоком. Анализ 35- и 100-дневной ОВ всех пациентов показал

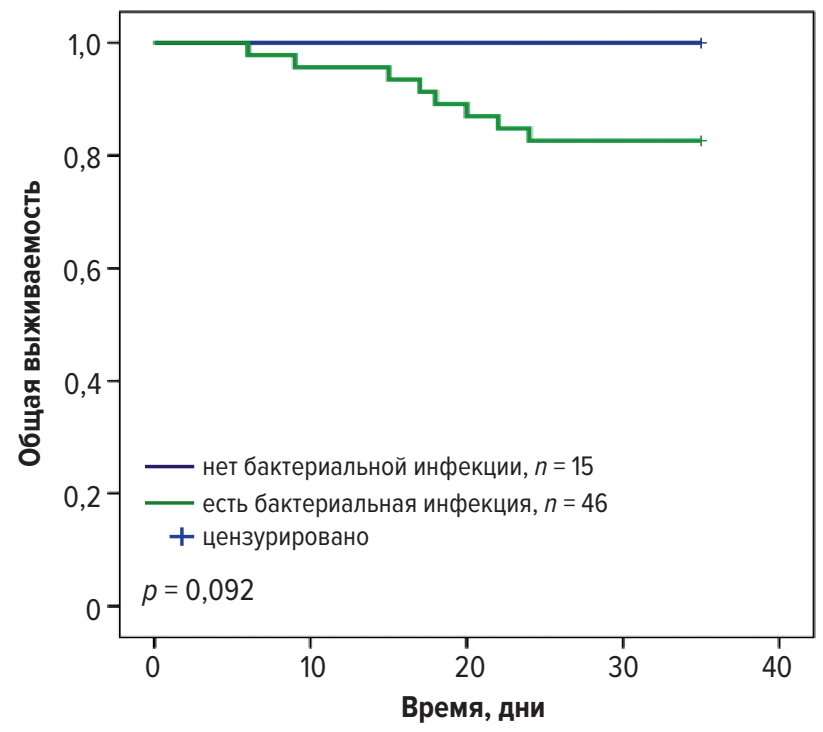

Рис. 8. Прогностическое влияние развития бактериальной инфекции на 35-дневную общую выживаемость

Fig. 8. Prognostic influence of bacterial infections on the 35-day overall survival

худшие результаты лечения больных с развитием тяжелых форм бактериальных инфекций (сепсис, септический шок). В то же время разницы в ОВ у больных без бактериальной инфекции и с развитием фебрильной нейтропении/инфекции кровотока не отмечено (рис. 10 и 11). 35- и 100-дневная ОВ у пациентов с сепсисом и септическим шоком составила 100 vs 35 \% и 85 vs 19 \% соответственно (рис. 12 и 13).

Возбудитель был выделен у 75 и 65,8 \% больных в группах «salvage» и «non-salvage» соответственно. Частота инфекций, связанных с грамотрицательными микроорганизмами, составила 46 и 85 \% соответственно. В группе больных с неблагоприятным статусом на момент гаплоТГСК чаще регистрировались инфекции, вызванные Klebsiella pneumoniae (70 vs 30,7 \%), в т. ч. обусловленные штаммами со множественной лекарственной устойчивостью (МЛУ) (71,4 vs 37,5 \% соответственно). Инфекции, связанные с грамположительными микроорганизмами, встречались только у больных из группы «non-salvage» и составили 4,3 \%. Структура бактериальных инфекций представлена в табл. 3.

Принимая во внимание выявленные различия в этиологии инфекционного процесса, дополнительно проанализировано влияние тяжелых форм бактериальных инфекций на ОВ в изучаемых группах пациентов.

Негативное влияние сепсиса и септического шока на исход терапии было выявлено только в группе «salvage»: пациенты с развитием сепсиса и септического шока имели худшие результаты (медиана OB 37 дней $v s$ не достигнута) (рис. 14 и 15). Вероятно, данный факт обусловлен предшествующим лечением таких пациентов с большим числом линий противоопухолевой терапии в анамнезе (медиана 5,8, диапазон 2,9-11,4 vs медиана 2,7, диапазон 1,0-3,3). Это приводит к увеличению длительности периода нейтропении IV степени (в т. ч. до начала режима кондиционирования) и селекции штаммов микроорганизмов с МЛУ. 
Таблица 2. Структура бактериальных инфекций в группах пациентов с различным статусом («salvage» и «non-salvage») ко времени гаплоТГСК

\begin{tabular}{|c|c|c|c|c|c|c|c|c|}
\hline \multirow[b]{2}{*}{ Статус } & \multicolumn{2}{|c|}{$\begin{array}{c}\text { Нет бактериальных } \\
\text { инфекций }\end{array}$} & \multicolumn{2}{|c|}{$\begin{array}{c}\text { Фебрильная нейтропения/ } \\
\text { инфекция кровотока }\end{array}$} & \multicolumn{2}{|c|}{$\begin{array}{c}\text { Сепсис/септический } \\
\text { шок }\end{array}$} & \multicolumn{2}{|c|}{ Всего } \\
\hline & абс. & $\%$ & абс. & $\%$ & абс. & $\%$ & абс. & $\%$ \\
\hline «Salvage» $(n=26)$ & 6 & 23,1 & 5 & 19,2 & 15 & 57,7 & 20 & 76,9 \\
\hline «Non-salvage» $(n=35)$ & 9 & 25,7 & 15 & 42,9 & 11 & 31,4 & 26 & 74,3 \\
\hline$p$ & \multicolumn{2}{|c|}{ H3 } & \multicolumn{2}{|c|}{$<0,05$} & \multicolumn{2}{|c|}{$<0,05$} & \multicolumn{2}{|c|}{ H3 } \\
\hline
\end{tabular}

Н3 - статистически незначимо.

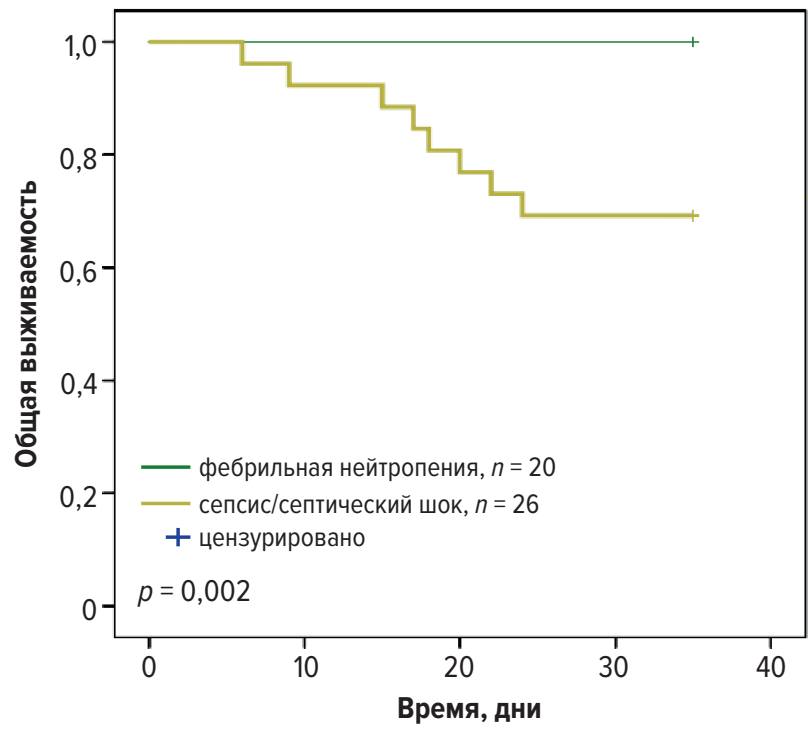

Рис. 10. 35-дневная общая выживаемость в группах пациентов с фебрильной нейтропенией, сепсисом/септическим шоком и без них после гаплоТГСК

Fig. 10. The 35-day overall survival in the groups of patients with and without febrile neutropenia, sepsis/septic shock after haploHSCT

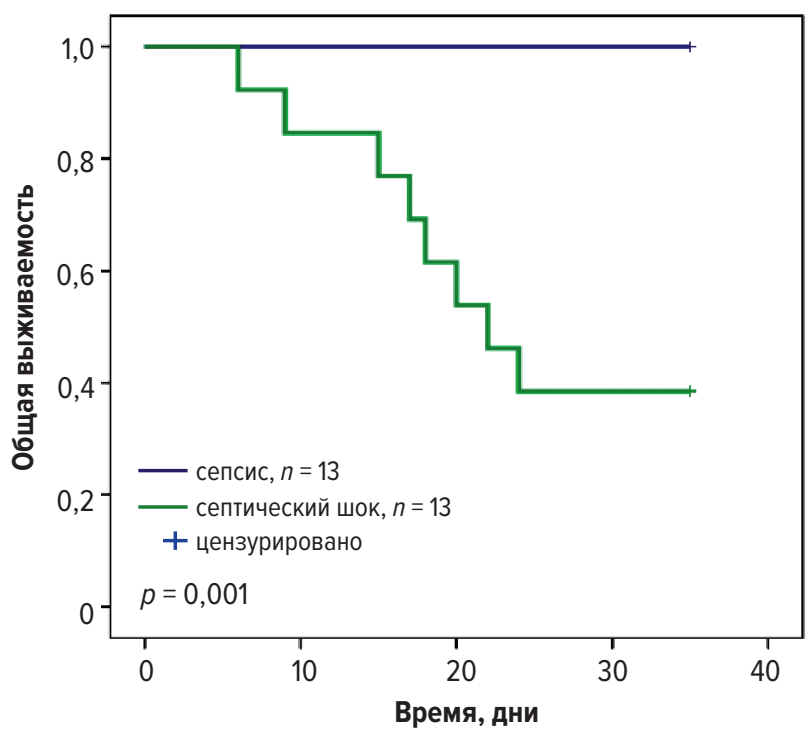

Рис. 12. 35-дневная общая выживаемость в группах пациентов с сепсисом и септическим шоком после гаплоТГСК

Fig. 12. The 35-day overall survival in the groups of patients with sepsis and septic shock after haplo-HSCT

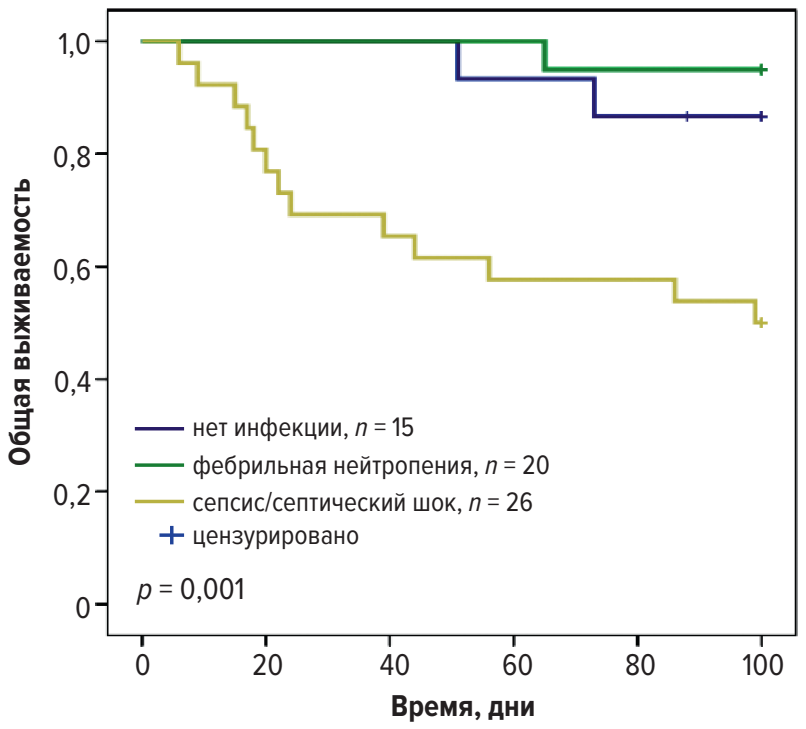

Рис. 11. 100-дневная общая выживаемость в группах пациентов с фебрильной нейтропенией, сепсисом/септическим шоком и без них после гаплоТГСК

Fig. 11. The 100-day overall survival in the groups of patients with and without febrile neutropenia, sepsis/septic shock after haploHSCT

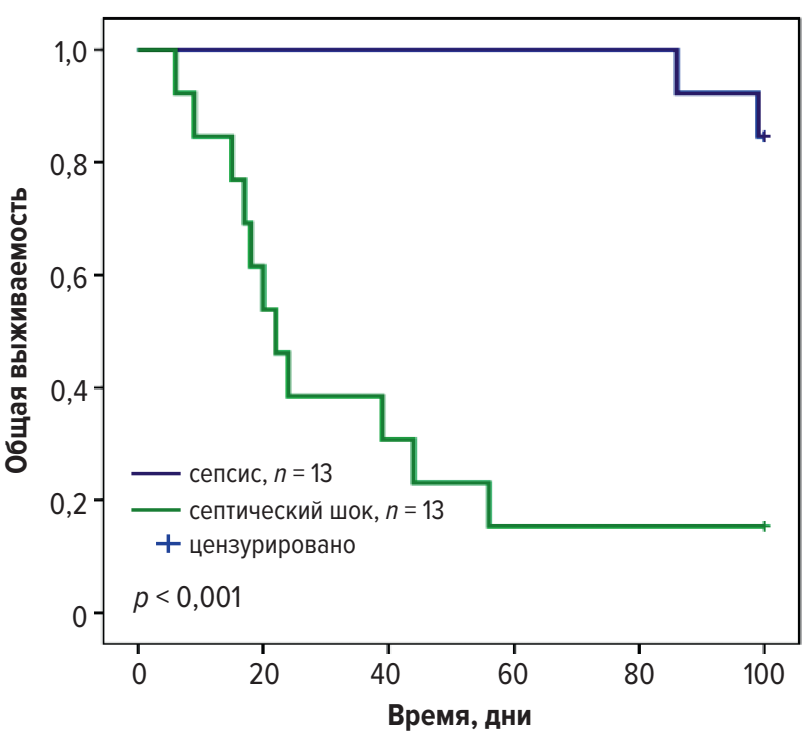

Рис. 13. 100-дневная общая выживаемость в группах пациентов с сепсисом и септическим шоком после гаплоТГСК

Fig. 13. The 100-day overall survival in the groups of patients with sepsis and septic shock after haplo-HSCT 
Таблица 3. Бактериальные инфекции в группах пациентов с различным статусом («salvage» и «non-salvage») ко времени гаплоТГСК

\begin{tabular}{|c|c|c|c|}
\hline Возбудитель & Общая группа $(n=61)$ & «Salvage» $(n=26)$ & «Non-salvage» $(n=35)$ \\
\hline Все бактериальные осложнения & $46(74,19 \%)$ & $20(76,9 \%)$ & $26(74,3 \%)$ \\
\hline Klebsiella pneumoniae & $22(47,8 \%)$ & $14(70,0 \%)$ & $8(30,7 \%)$ \\
\hline В т. ч. МЛУ-штаммы Klebsiella pneumoniae & $13(59,09 \%)$ & $10(71,4 \%)$ & $3(37,5 \%)$ \\
\hline Pseudomonas aeruginosae & $1(2,1 \%)$ & 0 & $1(3,8 \%)$ \\
\hline Stenotrophamonas maltophilia & $1(2,1 \%)$ & 0 & $1(3,8 \%)$ \\
\hline E. coli & $4(8,6 \%)$ & $2(10,0 \%)$ & $2(7,7 \%)$ \\
\hline Acinetobacter baumannii & $1(2,1 \%)$ & $1(5,0 \%)$ & 0 \\
\hline Микст-инфекция & $2(4,3 \%)$ & $2(10,0 \%)$ & 0 \\
\hline Все грамотрицательные возбудители (с учетом микст-инфекций) & $62,7 \%$ & $85 \%$ & $46 \%$ \\
\hline Staphylococcus hominis & $2(4,3 \%)$ & 0 & $2(7,7 \%)$ \\
\hline Нет данных & $17(36,9 \%)$ & $5(15,0 \%)$ & $12(34,2 \%)$ \\
\hline
\end{tabular}

МЛУ - множественная лекарственная устойчивость.

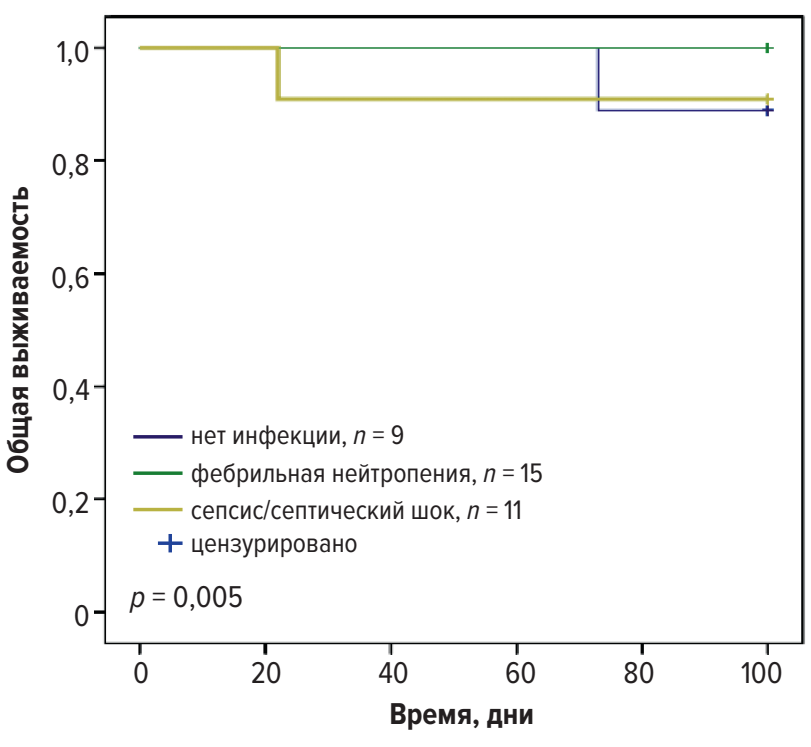

Рис. 14. Влияние степени тяжести бактериальной инфекции на 100-дневную общую выживаемость в группе «non-salvage»

Fig. 14. The influence of bacterial infection severity on the 100-day overall survival in "non-salvage" group

\section{ОБСУЖДЕНИЕ}

Таким образом, в структуре летальности при гаплоТГСК важное место занимают инфекционные осложнения. Установлено, что у пациентов обеих групп в ранний посттрансплантационный период преобладали бактериальные и вирусные (реактивация CMV) инфекции. Оценка частоты реактивации вируса герпеса 6-го типа не проводилась при отсутствии клинических проявлений этой инфекции. В первые 100 дней после гаплоТГСК частота реактивации CMV-инфекции составила 70,5 \%, развития ИМ - 11,5\%. Ни одно из указанных событий не влияло на ОВ пациентов в обеих группах. У больных с наличием в анамнезе ИМ эффективность вторичной противогрибковой профилактики составила $100 \%$.

Наиболее серьезную проблему, как и следовало ожидать, представляли бактериальные инфекции. Их частота составила 75,4 \%, при этом 100 \% эпизодов были зарегистрированы в период до нейтрофильного приживления трансплантата. Продемонстрировано

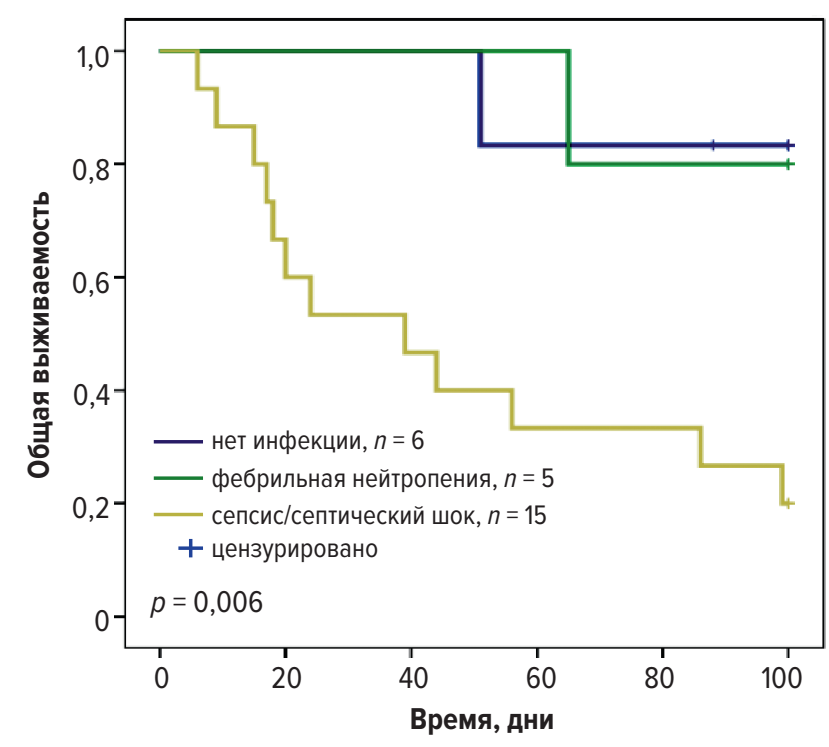

Рис. 15. Влияние степени тяжести бактериальной инфекции на 100-дневную общую выживаемость в группе «salvage»

Fig. 15. The influence of bacterial infection severity on the 100-day overall survival in "salvage" group

негативное влияние сепсиса и септического шока на 35- и 100-дневную ОВ, при этом худшие показатели зарегистрированы у пациентов с развитием септического шока по сравнению с сепсисом (100-дневная OB 38,5 vs $10 \%$; $p$ <,001). Прогностического влияния фебрильной нейтропении/инфекции кровотока на ОВ не продемонстрировано. Выявленная закономерность свидетельствует о возможности применения современных критериев диагноза Sepsis 3, в т. ч. у реципиентов аллогенных ГСК, что позволяет выделить группу больных с неблагоприятным прогнозом, нуждающихся в более агрессивной этиотропной и патогенетической терапии. Несколько неожиданным оказалось отсутствие прогностического влияния степени тяжести инфекционного процесса (сепсиса/септического шока vs фебрильная нейтропения/инфекция кровотока) в группе пациентов, которым трансплантация выполнена в ремиссии заболевания. Для объяснения данного феномена была проанализирована структура возбудителей в данных группах пациентов. В группе «salvage» было выявлено большее число бактериальных инфекций, связанных 
с микроорганизмами с МЛУ, - 71,4 vs 37,5 \%. Это представляет в настоящее время актуальную проблему во многих клиниках мира [20, 21].

В целом полученные в настоящем исследовании показатели OB оказались сопоставимыми с данными исследования SFGM-TC. Смертность, связанная с трансплантацией, в исследовании SFGM-TC [9] составила $21,5 \%(n=82)$, в т. ч. связанная с инфекционными осложнениями $-9,6 \%(n=37)$. В нашем исследовании при медиане наблюдения за пациентами 376 дней (диапазон 6-1202 дня) 1-летняя ОВ составила 49,3%, при этом статистически значимо лучшие показатели 1-летней ОВ были выявлены в группе пациентов, которым трансплантация выполнена при условии достижения оптимального противоопухолевого ответа ко времени гаплоТГСК $(68,7$ vs $25 \%$; $p<0,001$, лог-ранговый критерий). Медиана ОВ составила 974 и 86 дней соответственно ( $p<0,001)$, что согласуется с имеющимися в настоящее время результатами других исследований [9]. Частота летальных исходов, связанных с инфекционным процессом, составила $26,2 \%(n=16)$. При этом мы не обнаружили других причин смерти, которые могли бы рассматриваться в структуре летальности, связанной с трансплантацией. Таким образом, уровень такой летальности оказался сопоставимым.

\section{ЗАКЛЮЧЕНИЕ}

В заключение следует отметить, что гаплоТГСК является эффективным методом воздействия на опухоль у пациентов с рецидивами/рефрактерным течением онкогематологических заболеваний. Основным фактором, обусловливающим раннюю летальность, служат тяжелые бактериальные инфекции. Кроме того, наиболее значимым фактором риска является отсутствие ремиссии ко времени выполнения гаплоТГСК. Критерии Sepsis 3 могут использоваться у пациентов в период постцитостатической цитопении. Они позволяют выделить группу больных с максимально неблагоприятным прогнозом (развитие септического шока). Представляется, что в будущем, при появлении новых таргетных противоопухолевых средств, которые могут использоваться в качестве мост-терапии для подготовки к ТГСК, можно ожидать снижение уровня летальности, связанной с трансплантацией, за счет уменьшения количества инфекционных эпизодов. Внедрение в рутинную клиническую практику современных методов контроля над инфекцией (генотипирование штаммов с МЛУ и своевременное определение стратегии антимикробной химиотерапии с учетом полученных результатов) также будет способствовать улучшению результатов лечения таких больных с опухолями кроветворной и лимфоидной тканей высокого риска.

\section{КОНФЛИКТЫ ИНТЕРЕСОВ}

Авторы заявляют об отсутствии конфликтов интеpecoв.

\section{ИСТОЧНИКИ ФИНАНСИРОВАНИЯ}

Исследование не имело спонсорской поддержки.

\section{ВКЛАД АВТОРОВ}

Концепция и дизайн: Ю.С. Осипов, С.С. Бессмельцев, Г.Н. Салогуб.

Сбор и обработка данных: Ю.С. Осипов, Е.С. Михайлов, В.В. Иванов, Н.А. Жукова.

Предоставление материалов исследования: Ю.С. Осипов, Е.С. Михайлов, В.В. Иванов, Н.А. Жукова.

Анализ и интерпретация данных: Ю.С. Осипов, С.С. Бессмельцев, Г.Н. Салогуб.

Подготовка рукописи: все авторы.

Окончательное одобрение рукописи: А.В. Чечеткин, С.С. Бессмельцев, Г.Н. Салогуб.

Административная поддержка: А.В. Чечеткин, С.С. Бессмельцев.

\section{ЛИTEPATYPA/REFERENCES}

1. Поп В.П., Рукавицын О.А. Аллогенная трансплантация гемопоэтических стволовых клеток: перспективы и альтернативы, собственный опыт. Российский журнал детской онкологии и гематологии. 2017;4(2):46-69. doi: 10.17650/2311-1267-2017-4-2-46-69

[Pop VP, Rukavitsyn OA. Allogeneic transplantation of hematopoietic stem cells: Perspectives and alternatives, own experience. Russian Journal of Children Hematology and Oncology. 2017;4(2):46-69. doi: 10.17650/2311-1267-2017-4-246-69. (In Russ)]

2. Luznik L, O'Donnell PV, Ephraim JF. Post-transplantation cyclophosphamide for tolerance induction in HLA-haploidentical Bone Marrow Transplantation. Semin Oncol. 2012;39(6):683-93. doi: 10.1053/j.seminoncol.2012.09.005.

3. Luznik L, Fuchs EJ. High-dose, post-transplantation cyclophosphamide to promote graft-host tolerance after allogeneic hematopoietic stem cell transplantation. Immunol Res. 2010;47(1-3):65-77. doi: 10.1007/s12026-009-8139-0.

4. Burroughs LM, O'Donnell PV, Sandmaier BM, et al. Comparison of outcomes of HLA-matched related, unrelated, or HLA-haploidentical related hematopoietic cell transplantation following non-myeloablative conditioning for relapsed or refractory Hodgkin lymphoma. Biol Blood Marrow Transplant. 2008;14(11):1279-87. doi: 10.1016/j.bbmt.2008.08.014

5. Pagliardini T, Harbi S, Furst S, et al. Post-transplantation cyclophosphamidebased haploidentical versus Atg-based unrelated donor allogeneic stem cell transplantation for patients younger than 60 years with hematological malignancies: a single-center experience of 209 patients. Bone Marrow Transplant. 2018;54(7):1067-76. doi: 10.1038/s41409-018-0387-y.

6. Kasamon Y, Luznik L, Leffell M, et al. Nonmyeloablative HLA-haploidentical Bone Marrow Transplantation with high-dose post-transplantation cyclophosphamide: effect of HLA disparity on outcome. Biol Blood Marrow Transplant. 2010;16(4):482-9. doi: 10.1016/j.bbmt.2009.11.011.

7. Бессмельцев С.С., Абдулкадыров К.М. Множественная миелома: руководство для врачей. М.: СИМК, 2016. 512 с.

[Bessmeltsev SS, Abdulkadyrov KM. Mnozhestvennaya mieloma: rukovodstvo dlya vrachei. (Multiple myeloma: manual for physicians.) Moscow: SIMK Publ.; 2016. 512 р. (In Russ)]

8. Галстян Г.М., Макарова П.М., Кузьмина Л.А. и др. Успешная трансплантация аллогенного костного мозга у больных с тяжелым грамотрицательным сепсисом и септическим шоком. Клиническая онкогематология. 2014;7(2):122-30.

[Galstyan GM, Makarova PM, Kuzmina LA, et al. Successful allogeneic bone marrow transplantation in patients with severe gram-negative sepsis and septic shock. Klinicheskaya onkogematologiya. 2014;7(2):122-30. (In Russ)]

9. Fayard A, Daguenet E, Blaise D, et al. Evaluation of infectious complications after haploidentical hematopoietic stem cell transplantation with post-transplant cyclophosphamide following reduced-intensity and myeloablative conditioning: a study on behalf of the Francophone Society of Stem Cell Transplantation and Cellular Therapy (SFGM-TC). Bone Marrow Transplant. 2019. [ahead of print] doi: 10.1038/s41409-019-0475-7.

10. Kumar G, Ahmad S, Taneja A, et al. Severe sepsis in hematopoietic stem cell transplant recipients. Crit Care Med. 2015;43(2):411-21. doi: 10.1097/ ccm.0000000000000714.

11. Omrani AS, Almaghrabi RS. Complications of hematopoietic stem cell transplantation: Bacterial infections. Hematol Oncol Stem Cell Ther. 2017;10(4):228-32. doi: 10.1016/j.hemonc.2017.05.018. 
12. Alhemmari SH, Refaat $\mathrm{SM}$, Abdullah $\mathrm{AA}$, Abul M. Infectious complications after allogeneic bone marrow transplantation: Sheikha Badryia Center, Kuwait. Gulf J Oncol. 2015;1(18):79-86.

13. Freifeld AG, Bow EJ Sepkowitz KA, et al. Clinical practice guideline for the use of antimicrobial agents in neutropenic patients with cancer: 2010 update by the infectious diseases society of America. Clin Infect Dis. 2011;52(4):e56-e93. doi: 10.1093/cid/cir073.

14. EORTC International Antimicrobial Therapy Cooperative Group. Grampositive bacteraemia in granulocytopenic cancer patients. Eur J Cancer Clin Oncol. 1990;26(5):569-74. doi: 10.1016/0277-5379(90)90079-9.

15. Klastersky J. Science and pragmatism in the treatment and prevention of neutropenic infection. J Antimicrob Chemother. 1998;41(Suppl 4):13-24. doi: 10.1093/jac/41.suppl_4.13.

16. Mikulska M, Viscoli $C$, Orasch $C$, et al. Aetiology and resistance in bacteraemias among adult and paediatric haematology and cancer patients. J Infect. 2014;68(4):321-31. doi: 10.1016/j.jinf.2013.12.006.

17. Tomblyn M, Chiller T, Einsele H, et al. Guidelines for preventing infectious complications among hematopoietic cell transplantation recipients: a global perspective. Biol Blood Marrow Transplant. 2009;15(10):1143-238. doi: 10.1016/j. bbmt.2009.06.019.

18. De Pauw B, Walsh TJ, Donnelly JP, et al. Revised Definitions of Invasive Fungal Disease from the European Organization for Research and Treatment of Cancer/Invasive Fungal Infections Cooperative Group and the National Institute of Allergy and Infectious Diseases Mycoses Study Group (EORTC/MSG) Consensus Group. Clin Infect Dis. 2008;46(12):1813-21. doi: 10.1086/588660.

19. Abraham E. New Definitions for Sepsis and Septic Shock: Continuing Evolution but With Much Still to Be Done. JAMA. 2016;315(8):757-9. doi: 10.1001/ jama.2016.0290.

20. Gustinetti G, Mikulska M. Bloodstream infections in neutropenic cancer patients: a practical update. Virulence. 2016;7(3):280-97. doi: 10.1080/21505594.2016.1156821.

21. Wisplinghoff $H$, Seifert $H$, Wenzel RP, Edmond MB. Current trends in the epidemiology of nosocomial bloodstream infections in patients with hematological malignancies and solid neoplasms in hospitals in the United States. Clin Infect Dis. 2003;36(9):1103-10. doi: 10.1086/374339. 